\title{
Early Worsening of Retinopathy in Type 1 and Type 2 Diabetes After Rapid Improvement in Glycaemic Control: A Systematic Review
}

\author{
Handan Akil (D) · Jamie Burgess · Sarah Nevitt · Simon P. Harding • \\ Uazman Alam · Philip Burgess
}

Received: April 27, 2021 / Accepted: November 30, 2021 / Published online: December 20, 2021

(C) The Author(s) 2021

\section{ABSTRACT}

To systematically review the epidemiology of early worsening of diabetic retinopathy (EWDR) after substantial improvements in glycaemic control and evaluate characteristics including risk factors. This systematic review was registered with PROSPERO (CRD42020158252). An electronic literature search was performed according to PRISMA guidelines using MEDLINE, EMBASE, PubMed, Web of Science,

Uazman Alam and Philip Burgess are joint senior authors.

H. Akil $(\bowtie) \cdot$ S. P. Harding · P. Burgess

Department of Eye and Vision Science, Institute of Life Course and Medical Sciences, University of Liverpool and St. Paul's Eye Unit, Liverpool University Hospitals NHS Trust, Liverpool, UK e-mail: handanakil84@gmail.com

J. Burgess · U. Alam

Diabetes and Endocrinology Research, Institute of Cardiovascular and Metabolic Medicine and The Pain Research Institute, University of Liverpool and Liverpool University NHS Hospital Trust, Liverpool, UK

S. Nevitt

Department of Health Data Science, University of Liverpool, Liverpool, UK

\section{U. Alam}

Division of Endocrinology, Diabetes and Gastroenterology, University of Manchester, Manchester, UK
Scopus and Cochrane databases and manual reference for the articles published until 2020. Published full-text English language articles that report data on diabetic retinopathy in people with diabetes experiencing a rapid, substantial decrease in HbA1c after going through intensive therapy were included. All articles were screened, data were extracted and methodological quality was evaluated by two independent reviewers using a priori criteria. A total of 346 articles were identified after the removal of duplicates. Data were extracted from 19 full-text articles with a total of 15,588 participants. Included studies varied considerably in terms of patient selection, timing and method of assessing the eye and retinopathy classification. EWDR was reported to occur in a wide range of prevalences; $3.3-47 \%$ of participants within 3-84 months after intensification of glycaemic control. Risk factors for EWDR included long duration of diabetes, long-term uncontrolled hyperglycemia, amplitude of and baseline retinopathy severity in both type 1 and type 2 diabetes. The occurrence of EWDR and progression of retinopathy were found to have an association with the amplitude of HbA1c reduction. EWDR has been described in a proportion of people with intensification of glycaemic control. However, the prevalence remains unclear because of methodological differences in the identified studies. Future interventional studies should report 
retinopathy and visual outcomes using standardized protocols.

Keywords: Diabetes mellitus; Diabetic retinopathy; Early worsening of retinopathy; Intensive treatment

\section{Key Summary Points}

Why carry out this systematic review?

The aim is to review the epidemiology of early worsening of diabetic retinopathy (EWDR) after substantial improvements in glycaemic control.

What was learned from this systematic review?

The occurrence of EWDR and progression of retinopathy were found to have an association with the amplitude of HbA1c reduction.

\section{INTRODUCTION}

Diabetic retinopathy (DR) is the leading cause of vision loss in the working-age population in most industrialised countries [1, 2]. Globally, the number of people with diabetes was estimated to be 463 million in 2019 [1, 3-5] and this is expected to rise to more than 700 million by 2045 [3]. Amongst people with diabetes in the UK, the prevalence of DR and sight-threatening DR is estimated to be $32.4 \%$ and $3.4 \%$, respectively [6].

Modifiable risk factors for DR development and progression include poor glycaemic control, hypertension and dyslipidaemia [2, 7]. The relationship between glycaemic control and DR is complex, which is also mirrored in other microvascular complications such as diabetic foot disease [8] with a positive relationship with glycaemic variability. Diminished or absent glycaemic autoregulation or short falls of insulin availability are hypothesized to be the etiological factors for this glycaemic instability (variableness). It has been shown that if the patients with diabetes have exposure to intermittent high plasma glucose levels, they are more likely to have detrimental consequences compared to the patients who have exposure to constant high plasma glucose levels [9]. HbA1c variability is also associated with risk of DR requiring laser treatment in type 1 diabetes [10].

The average HbA1c in the UK is suboptimal and has been reported as $66 \mathrm{mmol} / \mathrm{mol}(8.2 \%)$ in type 1 diabetes [11] and $58 \mathrm{mmol} / \mathrm{mol}(7.5 \%)$ or lower in type 2 diabetes [12]. Good metabolic control and near-normalization of plasma glucose levels form the foundations of the management of diabetes mellitus and have been found to be effective in preventing microvascular complications including vision loss due to DR $[13,14]$. National Institute for Health and Care Excellence (NICE) guidelines advise to aim for a target $\mathrm{HbA} 1 \mathrm{c}$ level of $48 \mathrm{mmol} / \mathrm{mol}(6.5 \%)$ or lower in people with type 1 diabetes and $53 \mathrm{mmol} / \mathrm{mol}(7 \%)$ or lower in people with type 2 diabetes to minimise the risk of longterm vascular complications [12, 15]. Deterioration of DR upon initiation of intensive glycaemic control was first described in type 1 diabetes in the 1980s [16] and has been referred to as early worsening of diabetic retinopathy (EWDR). More recently, there have been reports of EWDR with intensification of glycaemic control with glucagon-like peptide 1 (GLP-1) receptor analogue therapy [17]. Although EWDR had temporary and limited impact in some patients, severe retinal damage occurred in others who had to receive laser treatment eventually. The mechanisms of EWDR are yet to be elucidated. Alterations in growth hormone, IGF-1 (insulin-like growth factor 1) axis and vascular endothelial growth factor (VEGF) secondary to rapid glycaemic improvement in the presence of hypoxia are thought to play a pivotal role [18]. Given that glycaemic control remains suboptimal in a large proportion of individuals with the subsequent aim to improve this to near normoglycaemic levels, a substantial number are at risk of EWDR.

Our aim was to systematically review the published literature on the epidemiology and characteristics of EWDR and determine its incidence and any risk factors. 


\section{METHODS}

\section{Search Strategy}

This systematic review was conducted in accordance with PRISMA guidelines [19] (protocol registered with PROSPERO: CRD42020158252). Electronic searches with methodological input from a medical librarian were performed to identify articles reporting the incidence of EWDR in the following databases: MEDLINE (access via OVID), EMBASE (access via OVID), PubMed, Web of Science, Scopus and Cochrane databases. An a priori search strategy was followed. Searches were restricted to those of English language from database inception to January 2020. Two investigators (HA and JB) independently conducted database searches. Combinations of pre-specified search terms were used (Table 1). Results from the databases were merged using Mendeley software to facilitate the removal of duplicates. Reference lists of identified studies, review articles and systematic reviews were manually reviewed to identify any additional studies. No funding or sponsorship was received for this study or publication of this article. The inclusion and exclusion criteria for selected studies are shown in Table 2.

The two authors independently screened the titles and abstracts identified by the searches according to eligibility criteria (Table 2). Fulltext articles were retrieved where studies appeared to be eligible from abstract screening; if there was any doubt regarding the eligibility of any given study, the paper was included for critique of the full text. Two authors (HA and JB) independently assessed the full-text articles, with the involvement of a senior author $(\mathrm{PB})$ in the event of disagreement. The process of screening and selection for inclusion was recorded using a PRISMA flowchart (Fig. 1).

\section{Data Extraction}

Data were extracted for the following fields: name of first author and study, year of publication, country, type of study and setting, participant characteristics including clinical and demographic data, and study results such as
Table 1 Search terms

\begin{tabular}{ll}
\hline $\begin{array}{l}\text { Diabetes or IT- } \\
\text { related terms }\end{array}$ & EWDR-related terms \\
\hline $\begin{array}{l}\text { 'Diabetes mellitus } \\
\text { type 1' }\end{array}$ & 'Diabetic retinopathy' \\
'Diabetes mellitus & 'Pre-proliferative diabetic \\
type 2' & retinopathy' \\
'Intensive insulin & 'Proliferative diabetic \\
treatment' & retinopathy' \\
'Intensive insulin & 'Worsening of diabetic \\
infusion treatment' & retinopathy' \\
'Insulin pump therapy' & 'Paradoxical phenomenon' \\
'Rapid improvement of & 'Early worsening diabetic \\
blood glucose' & retinopathy' \\
'Rapid blood glucose & 'Retinopathy progression' \\
control' & \\
'Large HbAlc & 'Early retinal damage' \\
reductions' & \\
'GLP-1 agonist & 'Paradoxical early aggravation of \\
therapy' & diabetic retinopathy' \\
'Insulin pump therapy' & 'Incidence' \\
'Uncontrolled diabetes' & \\
'Hyperglycemia' & \\
\hline
\end{tabular}

sample sizes, number of participants with worsening/progression of retinopathy. Extracted data were reviewed by a senior author (PB) to ensure accuracy. Data were extracted for cohorts that did not experience a rapid substantial reduction in HbA1c. Intensive therapy was defined [20] as a reduction of HbA1c of $11 \mathrm{mmol} / \mathrm{L}, 198 \mathrm{mg} / \mathrm{dl}(1 \%)$, or greater with pharmacotherapy (insulin or GLP-1 receptor agonist) and maintenance over a 6-month period. EWDR [21] was defined as development of new DR, worsening of DR grades in either eye, development of maculopathy as defined by each study or need for commencement of treatment for retinopathy or maculopathy including intravitreal anti-VEGF, laser and vitrectomy over the same period of time. 
Table 2 Inclusion and exclusion criteria

\begin{tabular}{lc}
\hline Inclusion criteria & Exclusion criteria \\
\hline $\begin{array}{l}\text { Adults over the age of } \\
18 \text { years who have diabetes } \\
\text { mellitus either type } 1 \text { or } \\
\text { type 2 defined by the }\end{array}$ & Not an original research \\
World Health & \\
$\begin{array}{l}\text { Organization (WHO) } \\
\text { [23, 24] and American } \\
\text { Diabetes Association } \\
\text { (ADA) criteria [25] }\end{array}$ \\
$\begin{array}{l}\text { Cohorts and observational } \\
\text { studies displaying the } \\
\text { retinopathy outcomes in } \\
\text { patient with diabetes and } \\
\text { who receive intensive } \\
\text { therapy }\end{array}$ \\
$\begin{array}{l}\text { Full-text publications } \\
\text { Not a human study }\end{array}$ \\
\end{tabular}

\section{Critical Appraisal}

A validated critical appraisal tool developed by Hoy et al. [22] was utilized to evaluate methodological quality and risk of bias in the included studies, specifically assessing the external and internal validity. HA and JB independently evaluated the quality of the studies, with the involvement of $\mathrm{PB}$ in the event of a disagreement and an a priori decision that the articles were not weighted on the basis of the risk of bias.

\section{Primary Outcome}

The primary outcome was incidence of new worsening of retinopathy. Incidence was calculated as the number of people with new worsening of retinopathy divided by the total number of people with DR on intensive therapy (IT) over a specified time. Methodological variables that could bias the reported incidence were extracted: study size, population, ethnicity, gender, time period of sampling method of assessment of diabetic retinopathy. These variables were tabulated and considered as sources of clinical heterogeneity.

\section{Data Analysis}

All selected articles were included in the systematic review. Clinical heterogeneity of the studies was assessed by comparing study designs and participant characteristics. The clinical heterogeneity was deemed to be high and therefore a reliable or useful pooled summary incidence estimate was not calculated. Therefore, a meta-analysis was not undertaken and a narrative review of the studies was performed. Data in the tables are expressed as means $( \pm$ SD or range when applicable).

\section{Compliance with Ethics Guidelines}

This article is based on previously conducted studies and does not contain any new studies with human participants or animals performed by any of the authors.

\section{RESULTS}

A total of 346 articles were identified from the electronic database and manual reference searches (Fig. 1). Titles and abstracts were screened using the eligibility criteria and 327 articles were excluded. Analysis of the full texts was performed, 20 of which fulfilled the inclusion criteria and from which data were extracted (Tables 3 and 4). The majority of studies were carried out in North American and European populations. The study sample sizes ranged 


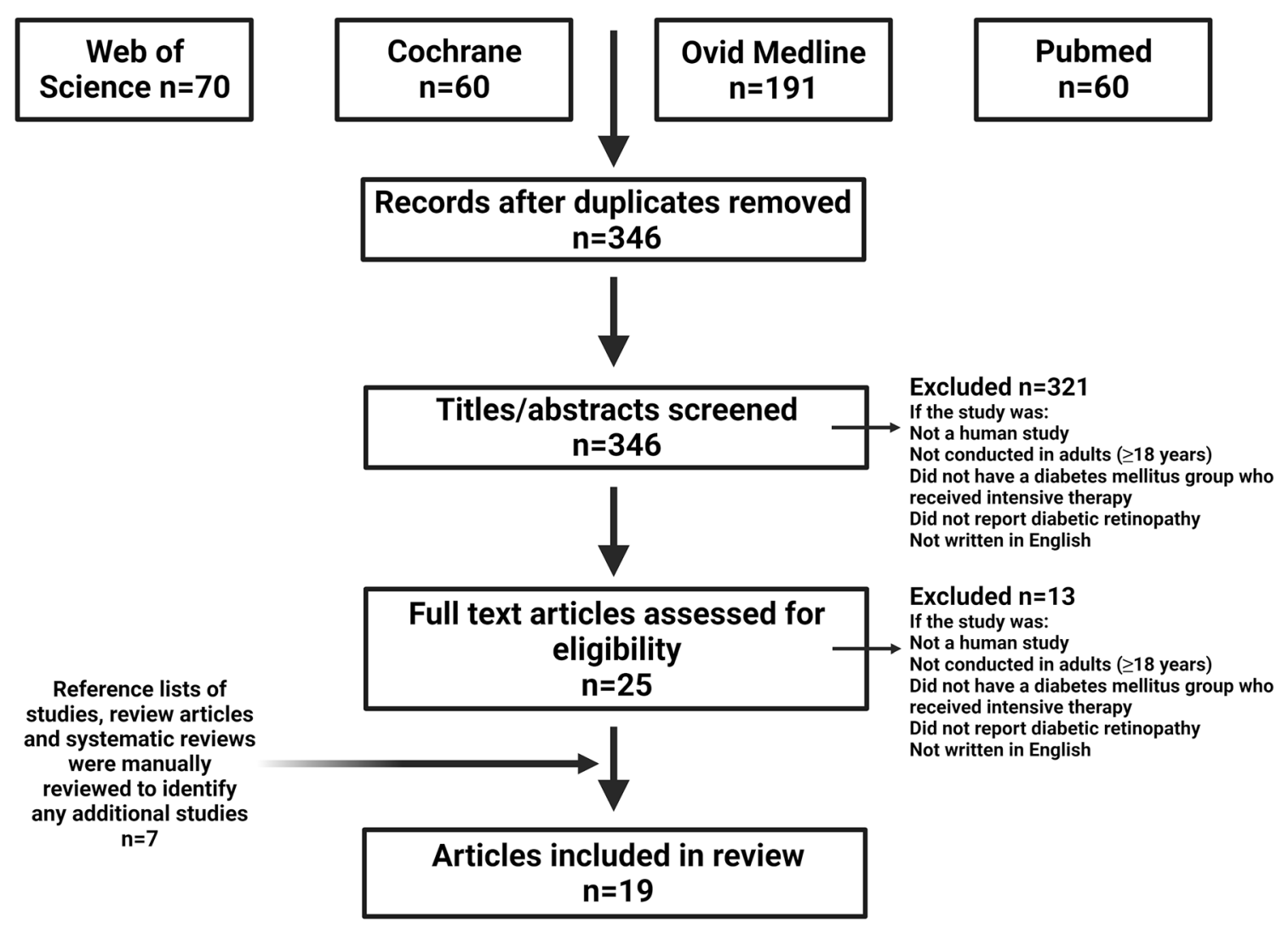

Fig. 1 PRISMA flow diagram for the systematic review detailing the database searches, the number of abstracts screened and the full texts retrieved. Created with BioRender.com

from 30 to 3867 participants [26, 27]. None of the studies included reported an appropriate sample size calculation for DR outcomes and some had low numbers of participants. Several studies were hospital based and also recruited participants from a single centre whilst others did not detail recruitment strategies.

\section{EWDR in Type 1 Diabetes Mellitus}

Steno [26, 28], Oslo [29, 30], Kroc [31, 32], DCCT study [33] and Klefter et al. [34] reported EWDR in type 1 diabetes receiving intensive therapy.

\section{Studies Characteristics}

Steno [26, 28], Oslo [29, 30], DCCT study [33] and Kroc [31, 32] studies were prospective randomised clinical trials which compared intensive and conventional treatment (CT) groups. Klefter et al. [34] reported a prospective controlled study comparing two groups, the first commencing insulin pump therapy and the second continuing multiple daily insulin injections. Treatment regimens were pre-planned i.e. participants were not randomized. There was a wide variation in study sample sizes which ranged from 30 to 1441 participants [26, 27]. The duration of follow-ups ranged from 8 months [31] to nearly 7 years but most studies reported annually [35-37]. All the studies were carried out in the USA and Europe and are summarized in Table 3.

\section{Intensive Therapy}

There was no consistent definition of IT in these studies but a reduction in $\mathrm{HbA} 1 \mathrm{c}$ of $1.5 \%$ over 3 months $[31,38]$ (e.g. an HbA1c decrease from $9 \%$ to $7.5 \%$ ) or more than $2 \%$ over a 6 -month 


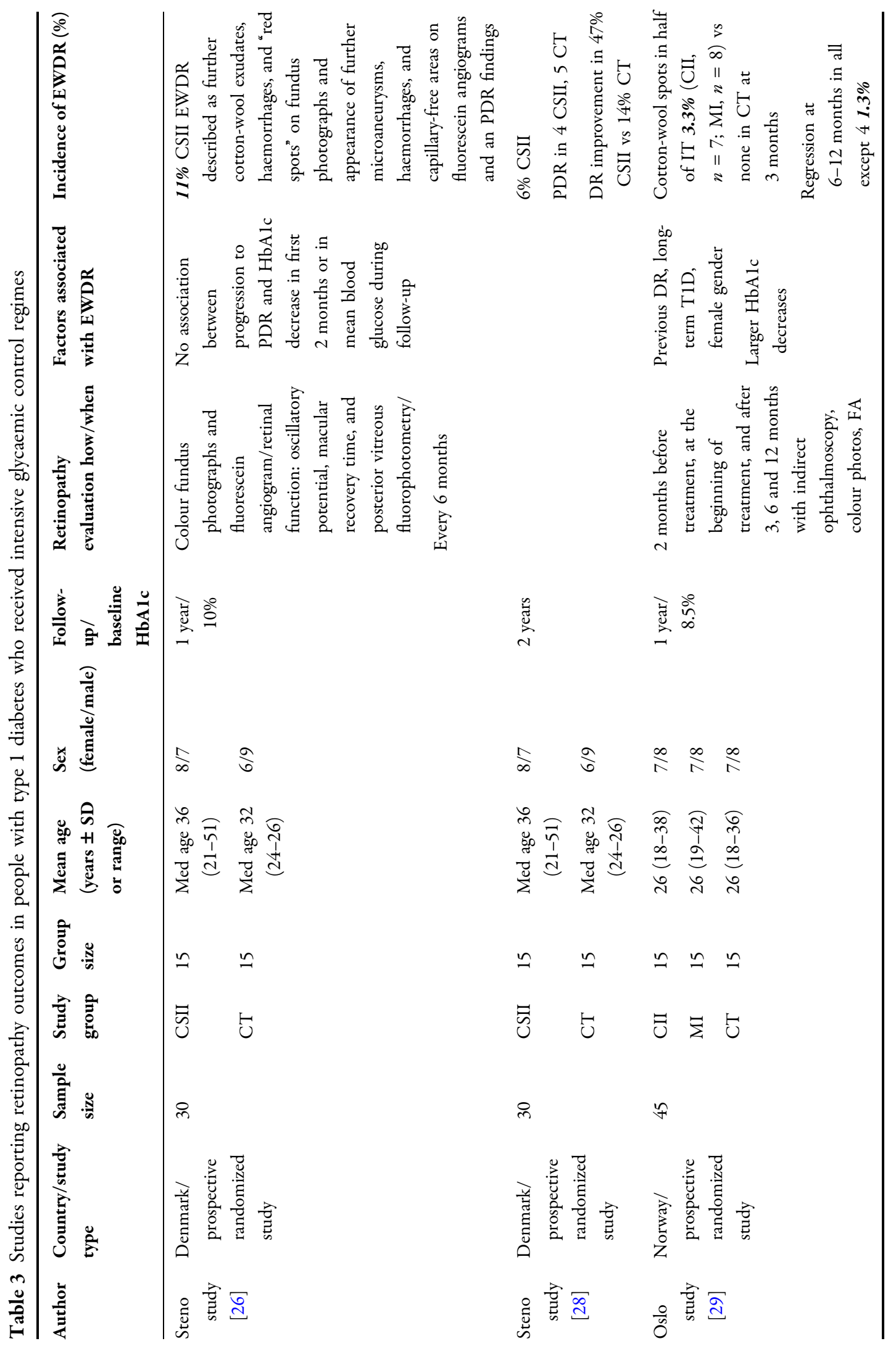




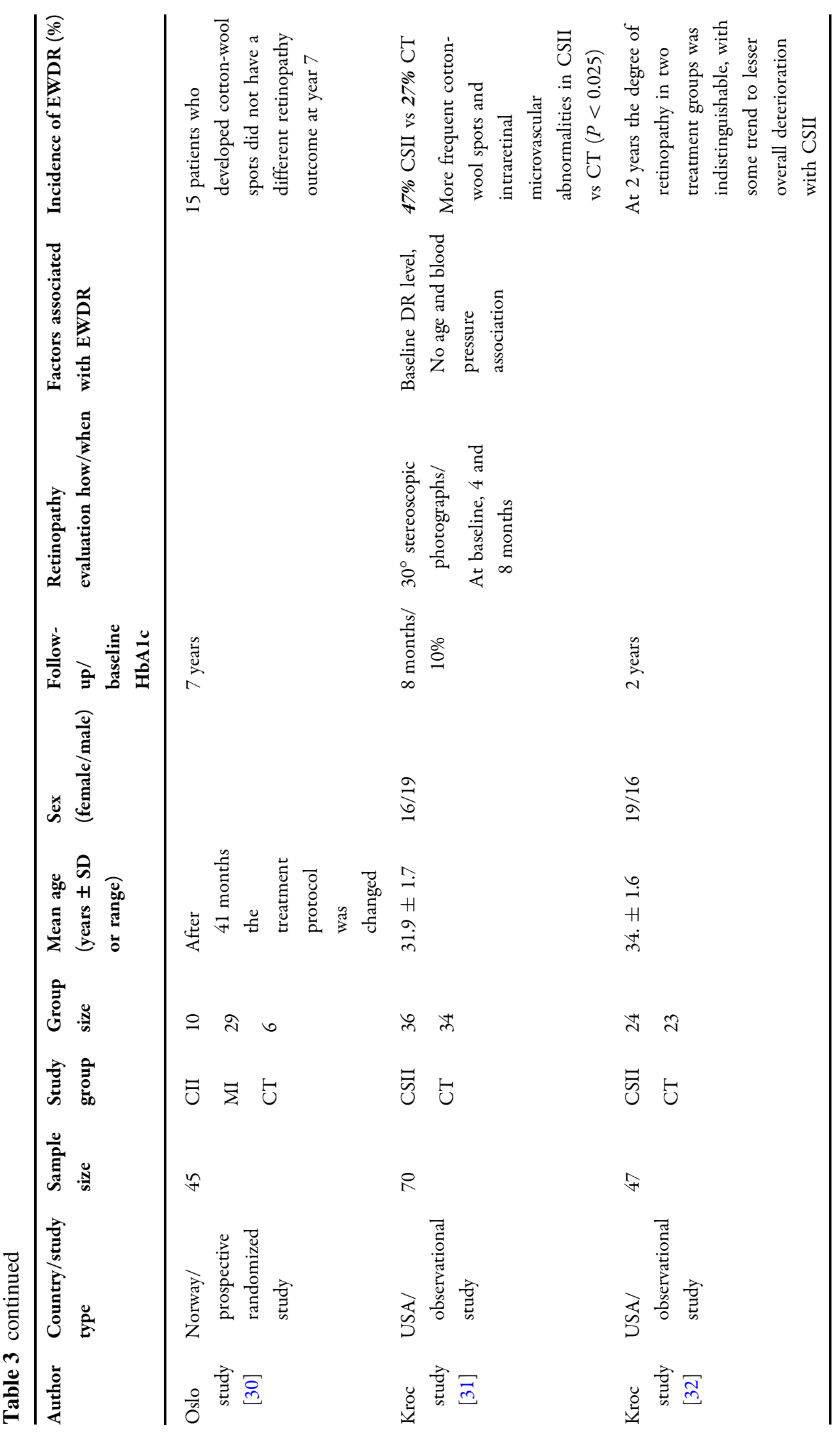




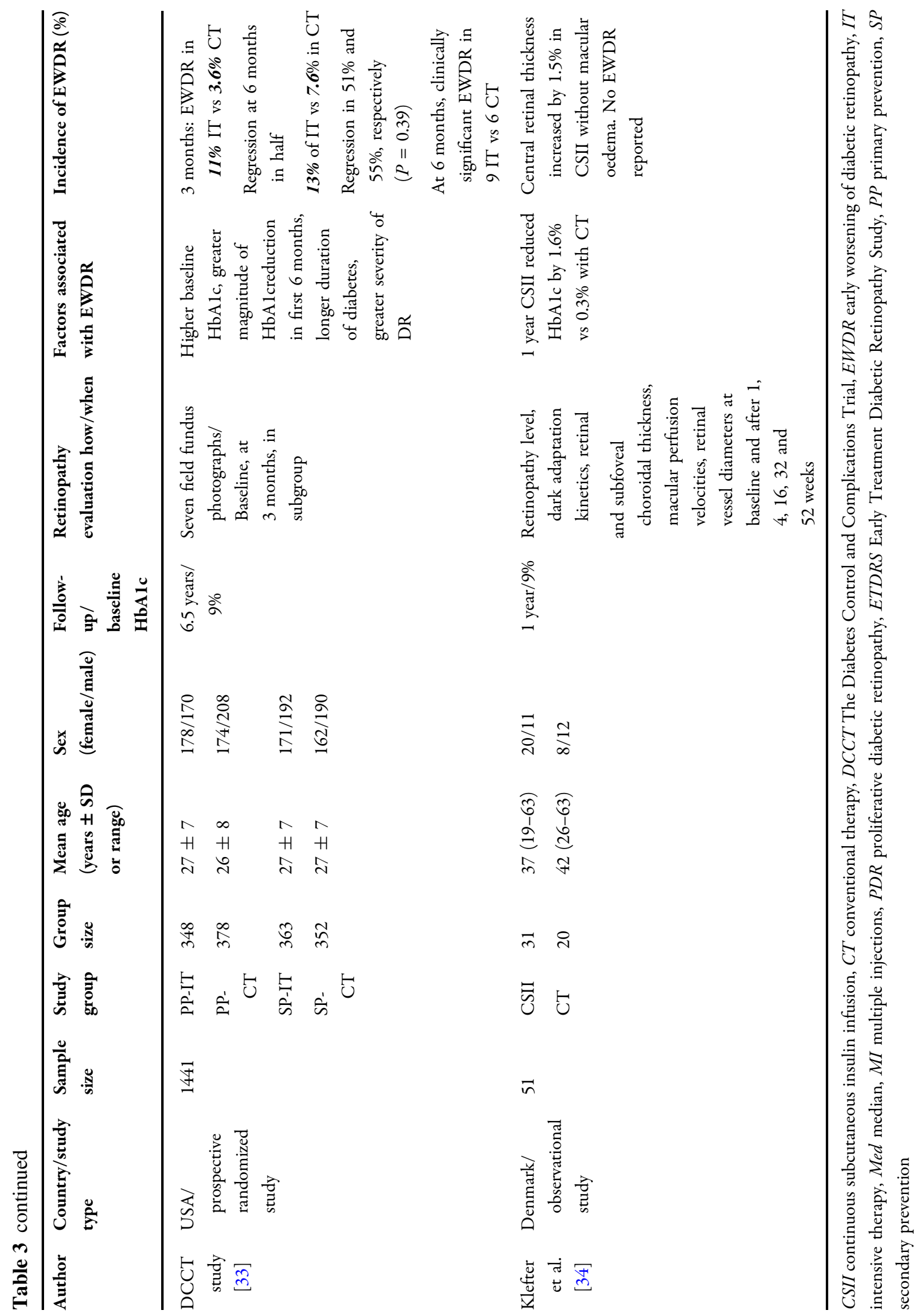




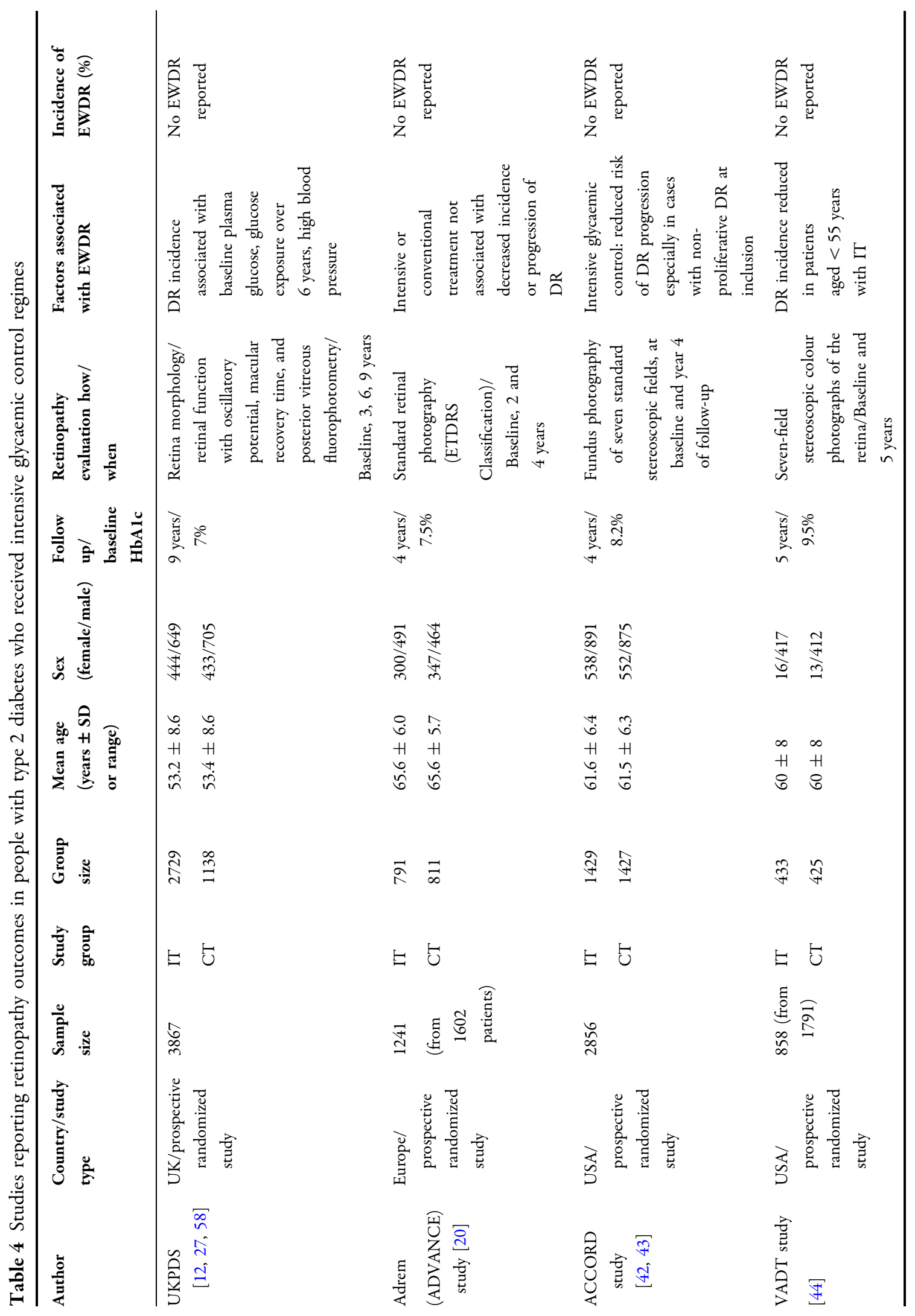




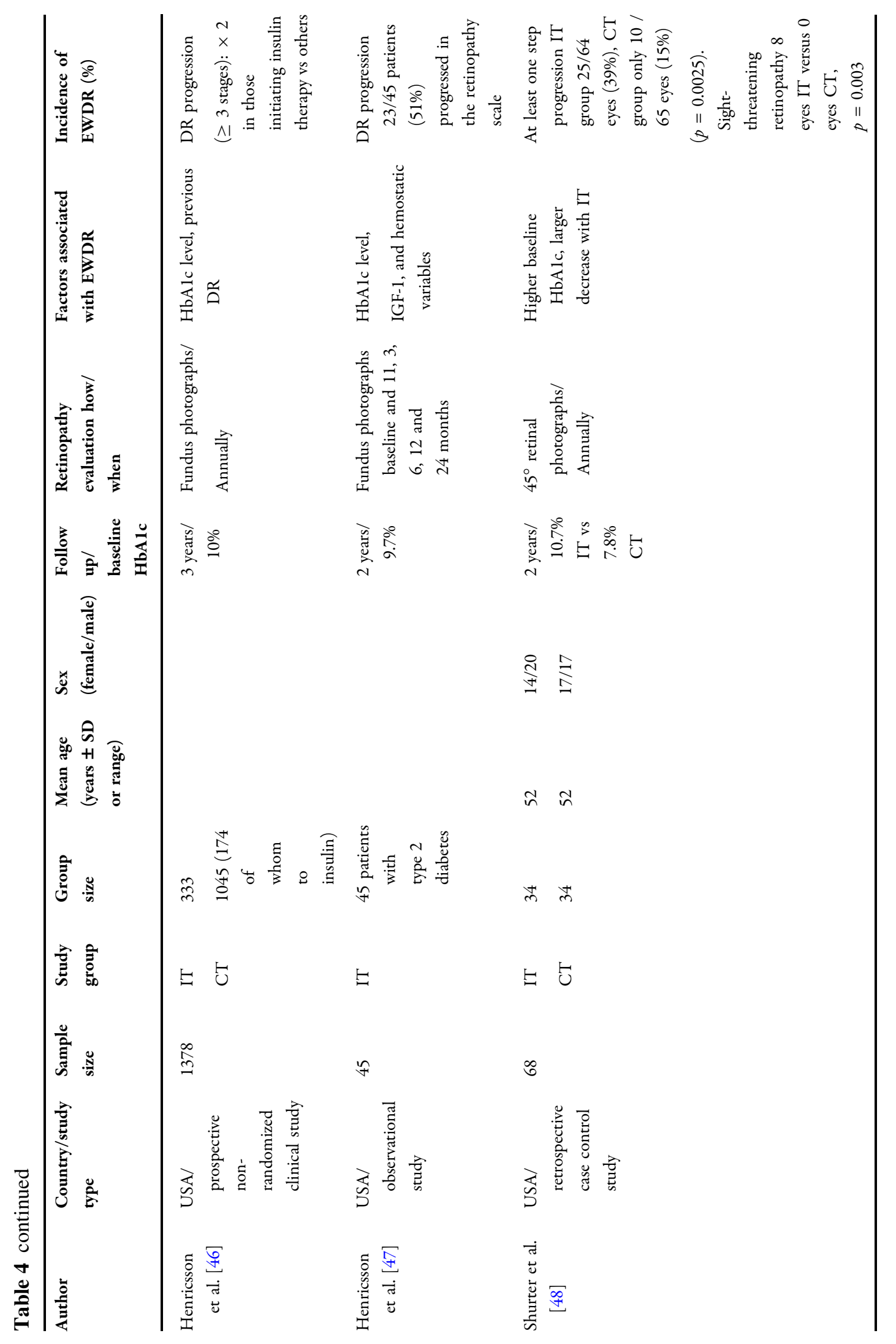




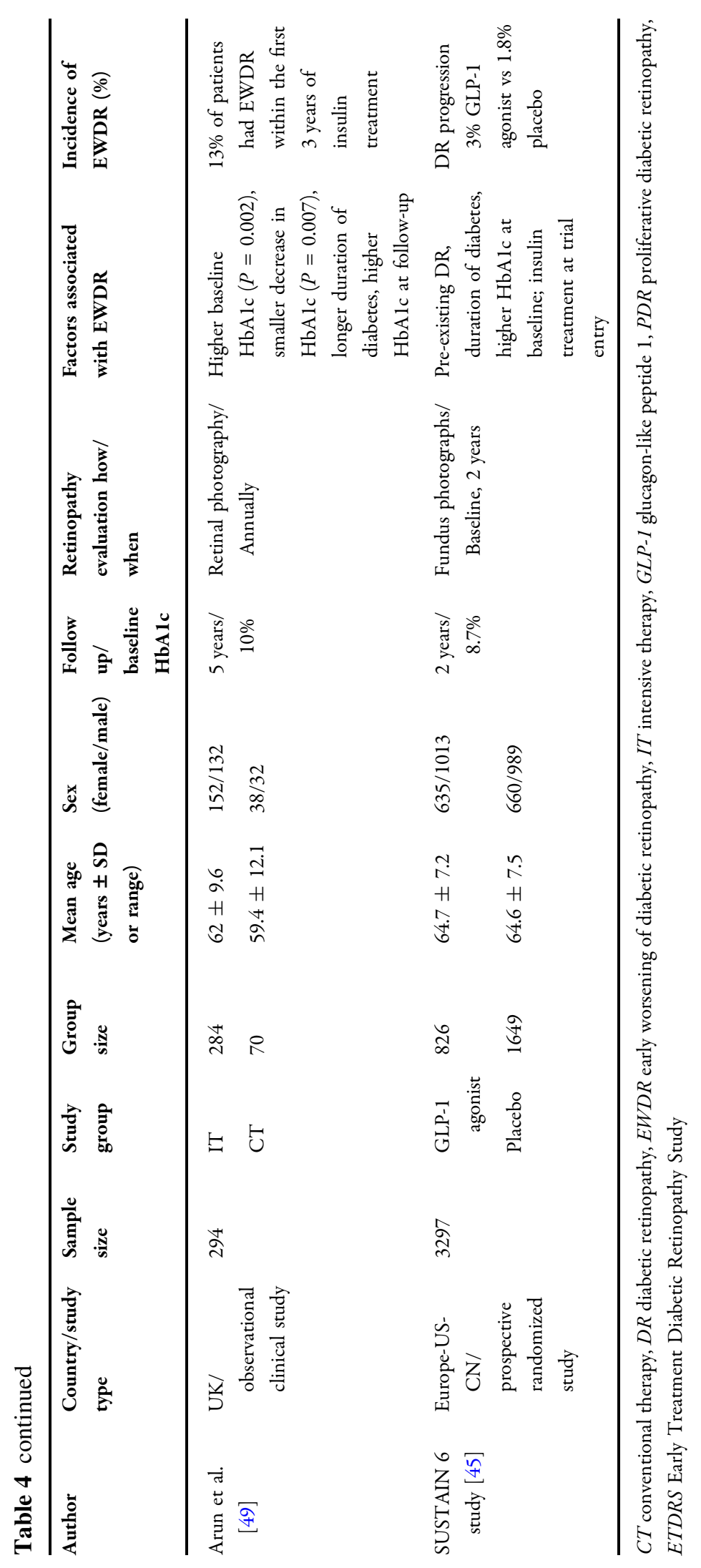


period $[26,38]$ after the commencement of subcutaneous insulin infusion or multiple injections of insulin were commonly reported. The DCCT study [38] described IT as administration of insulin at least three times by injection or an external pump. The goal was to achieve preprandial plasma glucose concentrations between 70 and $120 \mathrm{mg} / \mathrm{dl}(0.79$ and $1.36 \mathrm{SI}$ units) postprandial concentrations of less than $180 \mathrm{mg} / \mathrm{dl}$ and $\mathrm{HbA} 1 \mathrm{c}$ level of less than $6.5 \%$, measured monthly. In the Oslo study [29], participants were randomly assigned to two different modes of intensive treatment: either continuous subcutaneous insulin infusion or multiple insulin injections. In the multiple daily injection group, rapid-acting insulin was administered before each meal (four to six times daily) with isophane insulin at bedtime. The investigators did not set a target for HbA1c reduction or level but reported that the mean plasma glucose concentration improved substantially with the introduction of IT and remained near normal (preprandial plasma glucose concentrations between 70 and $120 \mathrm{mg} /$ $\mathrm{dl}$ and postprandial concentrations of less than $180 \mathrm{mg} / \mathrm{dl}$ ) for 1 year. No such improvement was observed in the control group. Steno study [26] participants were randomly allocated to either an IT group who received continuous subcutaneous insulin infusion (CSII) aiming for postprandial glucose values below $9 \mathrm{mmol} / \mathrm{l}$ $(162 \mathrm{mg} / \mathrm{dl})$ and no glucosuria or to a CT group who received two daily injections of insulin aiming for postprandial morning plasma glucose excretion below $15 \mathrm{mmol} / \mathrm{l}(270 \mathrm{mg} / \mathrm{dl})$ and $24 \mathrm{~h}$ urinary glucose excretion below $20 \mathrm{~g}$.

\section{Assessment of Retinopathy}

Methods of assessment and classification of retinopathy varied widely. The studies were carried out between 1983 [26] and 2016 [34] and utilized different modalities for the evaluation of diabetic retinopathy with advances in technology. Follow-up intervals ranged from 3 months to annual examinations. Seven field fundus photographs were used in the DCCT study [38], $30^{\circ}$ stereoscopic photographs were analyzed in the Kroc study [32], macular and choroidal thickness was measured with optical coherence tomography (OCT) in one study [34] and indirect ophthalmoscopy was performed in the Oslo [29] and Steno studies [26]. The majority of studies used an adaptation of the Early Treatment Diabetic Retinopathy Study grading system [39]. There was no external validation of the retinopathy grading in any study. Ophthalmological examinations were performed at least annually, although early evaluation was performed within the first 3 months of IT in two studies. In the Oslo study, the participants were examined 2 months before the randomization to be able to have a baseline grading, and at 3, 6 and 12 months [29]. A subgroup of the DCCT cohort was examined at 3 months [33, 35].

\section{Description of Populations of Included Studies}

The Steno [26], Kroc clinical trials [31] and Klefter et al. [34] recruited participants who had non-proliferative DR at baseline and excluded participants with proliferative DR. The Oslo study [29] and DCCT [38] primary prevention cohort study participants did not have any DR at the beginning of the study. The Oslo clinical trial [29], DCCT [38] and Klefter et al. [34] reported baseline HbA1c levels greater than $69 \mathrm{mmol} / \mathrm{mol}(8.5 \%)$. Steno [26] and Kroc studies [31] reported baseline HbA1c around $10 \%$. Tight plasma glucose control in most cases who received IT had $11-33 \mathrm{mmol} / \mathrm{mol}(1-3 \%)$ reductions in HbA1c levels at their first year of follow-up [31, 38].

The Steno study recruited 30 participants with insulin-dependent diabetes mellitus with long-term hyperglycemia (type 1 diabetes, approximately with a duration of 20 years) and moderate non-proliferative DR $[26,28]$. In 1983, IT group showed progression of DR after 1 year of treatment. The frequency of deterioration was found to be highest in the IT group, especially among the ten participants with the best glycaemic control. Proliferative retinopathy developed in three patients, two of which had IT. Retinal function which was evaluated by oscillatory potential, macular recovery time, 
and posterior vitreous fluorophotometry, improved significantly with IT and deteriorated significantly with CT. Changes in retinal function were most pronounced in participants with the greatest and the poorest regulated glycaemic control. At 2 years, four participants in the IT group and five in the CT group developed proliferative retinopathy [28]. However, a significant trend was found toward more frequent improvement of retinal morphology in the IT group (47\%) than in the CT group (13\%).

In the Oslo study, 45 people with insulindependent (type 1) diabetes with non-proliferative DR were randomized to receive either continuous subcutaneous insulin infusion, multiple insulin injections, or conventional insulin treatment [36]. Angiogram evaluation showed progression of retinopathy in the CT group, transient deterioration in the continuous infusion group, and no change in the multiple injection group. Half the participants receiving IT $(n=7)$ and multiple injections $(n=8)$ developed retinal cotton-wool spots within 6 months of follow-up. These changes regressed in all except four participants after 12 months. The Kroc collaborative study reported $47 \%$ of participants receiving IT worsened at 8 months compared to the CT group, nearly $30 \%$ of which showed worsening of DR [31].

DCCT study is the landmark trial in type 1 diabetes which provided a novel insight regarding the frequency and the risk factors for EWDR in IT [35]. A subgroup of participants were reported to experience the sustained progression of retinopathy by three or more steps on the ETDRS scale at 3 months; $11 \%$ with IT vs $3.6 \%$ with CT. At the 6-month and/or 12-month visits, progression was observed in significantly more participants randomized to receive IT (13.1\%) than CT (7.6\%). At 18 months follow-up, DR was found to be improved in $51 \%$ of participants in the IT group and $55 \%$ of participants in the CT group. Participants with early worsening phenomenon had higher HbA1c at baseline and experienced greater reductions in $\mathrm{HbA} 1 \mathrm{c}$ during the first 6 months of treatment compared to those without. However, despite this initial deterioration in DR, the IT group had similar or more favourable retinopathy grading outcomes compared with conventionally treated participants at 12 months. After 10 years, once HbA1c levels had become comparable between the two treatment groups, the risk of DR progression was still significantly lower in IT compared with CT. This beneficial effect persisted for up to 18 years $[40,41]$ and was termed as 'metabolic memory'. Clinically, the emergence of this term suggests the need for a early aggressive treatment of metabolic control and the addition of agents which reduce cellular reactive species and glycation in addition to normalizing glucose levels in order to minimize long-term diabetic complications.

\section{EWDR in Type 2 Diabetes Mellitus}

The UKPDS [27], Adrem [20], ACCORD [42, 43], VADT [44], SUSTAIN 6 [45], Henricsson et al. [46, 47], Shurter et al. [48] and Arun et al. [49] studies evaluated DR progression after tight control of plasma glucose levels in type 2 diabetes (Table 4).

\section{Design}

Five prospective randomized clinical trial were identified [20, 27, 42, 44, 45]. Hospital-based clinical studies were reported by Henricsson et al. [46, 47] and Arun et al. [49]. None of these large randomized clinical studies evaluating the benefits of IT on microvascular events included early retinal evaluation. Shurter et al. evaluated 68 people with type 2 diabetes retrospectively [48]. Randomised clinical trial of IT versus CT was the primary methodology used $[20,27,43,44]$.

\section{Setting/Population}

The eight studies were performed in Europe and North America. Four studies were undertaken in Europe [20, 27, 49], three in the USA [42, 44, 47] and one was an international study which recruited participants in Canada, USA and Europe [45]. The number of participants varied between 3867 in the UKPDS [27] and 68 in a retrospective study conducted by Shurter et al. [48]. Study populations differed in terms of 
baseline glucose control and retinal status. The UKPDS included newly diagnosed patients with a low prevalence of DR at baseline [27], and the AdRem [20], ACCORD eye study [42] and VADT [44] all involved patients with 10-year duration of diabetes, high vascular risk and high DR prevalence at baseline.

\section{Intensive Therapy}

There was no precise definition of IT in these studies and baseline HbA1c levels differed between $53 \mathrm{mmol} / \mathrm{mol}(7 \%)$ and $86 \mathrm{mmol} / \mathrm{mol}$ (10\%). IT was defined as an HbA1c decrease of more than $1.5 \%$ over a period of subcutaneous insulin infusion or multiple daily injections of insulin or GLP-1 receptor agonists $[20,27,45,46,48-51]$.

\section{Assessment of Retinopathy}

Fundus photography was used as a retinal assessment method. ETDRS retinopathy classification was utilized in the AdRem study [20] and the UKPDS [27]. There was no external validation of the retinopathy grading in these studies except the UKPDS. Participants had eye examinations at baseline and at the end of the follow-up period. Baseline retinopathy grading (status) differed across these studies. Additionally, these studies had different criteria to define DR progression and need for the treatment $[20,27,42,51]$.

\section{Description of Populations of Included Studies}

The UKPDS included newly diagnosed participants with a low prevalence of DR at baseline [27], whereas the AdRem [20], ACCORD eye study [42, 43] and VADT [44] all involved participants with approximately 10-year durations of diabetes, high vascular risk and higher DR prevalence at baseline. While the UKPDS $[13,27,52]$ and ACCORD eye study [42, 43] demonstrated significant retinal mid-term benefits (improved glucose control) for the incidence or progression of DR in IT, the AdRem study and VADT [20, 44] did not. In these studies, no cases of EWDR were mentioned in side-effects reports. DR progression was similar to ADVANCE whose HbA1c levels decreased by more than $5.5 \mathrm{mmol} / \mathrm{mol}(0.5 \%)$ at 6 months [44]. In the ACCORD eye study, IT with HbA1c at baseline greater than $64 \mathrm{mmol} / \mathrm{mol}(8 \%)$ had similar DR progression to CT $(P=0.93)$, even though IT participants at 1 year had achieved a median HbA1c of $47 \mathrm{mmol} / \mathrm{mol}$ (6.4\%) and CT participants had a median HbA1c of $59 \mathrm{mmol} / \mathrm{mol}(7.5 \%)[42,43]$.

Henricsson et al. reported a non-randomized clinical trial including 1378 participants with T2D, among whom 333 were taking insulin, with 1045 using oral agents or diet alone at beginning of the study [46]. Of these participants, 174 received insulin therapy during follow-up. Two-fold increase of DR progression was noted in those participants who had switched to insulin therapy from oral hypoglycemic drugs. The main risk factors associated with DR progression were HbA1c status and DR severity prior to insulin therapy $(P<0.01)$. Henricsson et al. also reported another observational study of 45 patients with type 2 diabetes who were examined every 3 months during the first year of insulin therapy and followed up at month 24 [47]. The group used the Wisconsin scale to be able to grade DR on fundus photographs. They additionally measured HbA1c, IGF-1, and some hemostatic variables. In their study, DR progression of at least three levels (Wisconsin scale) was found to be related to the amount of HbA1c reduction, the duration of diabetes, but not to IGF-1 levels.

A retrospective case control study of 68 participants with type 2 diabetes reported EWDR [48]. Participants who experienced a decrease of more than $1.5 \%$ over 2 years were categorized as IT (control group had only small HbA1c alterations); 39\% of the IT group showed at least one step of progression change in retinopathy grade, compared with the CT group who only experienced minimal retinopathy change (39\% vs $15 \%$, respectively; $P=0.02$ ). Sight-threatening retinopathy was observed more in IT.

Data from Arun et al. [49] showed DR progression within the first 3 years of intensive treatment with insulin of 294 participants with type 2 diabetes (mean HbA1c of $10 \%$ at 
baseline). DR progression was defined as the development of moderate non-proliferative DR or higher grades of retinopathy or sight-threatening maculopathy on follow-up. Administration of laser therapy was considered as significant progression in those patients with moderate or severe non-proliferative DR at baseline. DR progression risk was found to be low in participants who did not have any DR at the baseline (2.6\%); however, EWDR was observed mostly in participants with moderate non-proliferative DR at inclusion. The risk factors in association with early worsening and sight-threatening retinopathy were discussed as high baseline HbA1c levels, long duration of uncontrolled diabetes and high mean HbA1c levels.

The SUSTAIN clinical trial $(n=3297)$ studied the efficacy and safety of semaglutide, a GLP-1 receptor analogue, for the treatment of type 2 diabetes in a high cardiovascular risk population [45], 29.4\% had pre-existing DR at baseline. Over 2 years, semaglutide was associated with a significant increase in the risk of DR complications compared to placebo group. Associations for EWDR were higher baseline HbA1c, a longer duration of diabetes and those with pre-existing retinopathy.

\section{Glucagon-Like Peptide (GLP)-1 Receptor Analogue Studies}

The SUSTAIN clinical trial studied cardiovascular outcomes with semaglutide (GLP-1 receptor analogue) in participants with type 2 diabetes and found the rate of DR complications such as loss of vision, vitreous haemorrhage, need for treatment were greater with semaglutide vs placebo $(P \leq 0.05)$ [45]. The incidence rate of confirmed events was highest in participants with HbA1c reductions greater than $1.5 \%$ with semaglutide or placebo. DR complications occurred less in the semaglutide group and especially in those with historical DR complications prior to recruitment. Conversely, in the Liraglutide Effect and Action in Diabetes: Evaluation of Cardiovascular Outcome Results (LEADER) randomized trial, incidence of DR complications was no different in type 2 diabetes with liraglutide compared to placebo [53]. The DR outcome difference may be attributed to the fact that the magnitude of HbA1c reduction was greater in SUSTAIN 6 compared to LEADER. Importantly, neither of these clinical trials was designed to evaluate DR events. The eye events were collected from the adverse event reports and additionally they did not have standard ophthalmological documentation and reporting in their protocols $[17,53]$. EWDR may be attributed to the recruitment of participants with advanced retinopathy, and EWDR observed in the first 4 months of the trial may be explained by the rapid and large HbA1c reductions rather than direct retinal toxicity [45]. Previous studies of GLP-1 receptor agonists have not shown worsening of DR either in vitro or in vivo [54].

\section{DISCUSSION}

This systematic review identified 19 publications reporting retinopathy data in people with diabetes receiving intensive therapy (total number of participants 15,588). Fifteen out of 19 publications reported EWDR as defined by study specific criteria. In studies reporting EWDR the range of incidence was $3.3-51 \%$ (Fig. 2). Those studies reporting EW identified the phenomenon in the time range 3-84 months from initiation of intensive therapy.

Reported risk factors for EWDR were duration of diabetes, baseline DR severity and longterm uncontrolled hyperglycemia in both type 1 and type 2 diabetes [29, 38, 49, 55]. The occurrence of EWDR and DR progression were found to have an association with the amplitude of HbA1c reduction [29, 38, 48, 49, 55]. Additionally EWDR was found to be more common in women than men in the Oslo study [36]. There are conflicting reports of whether EWDR is associated with insulin, as opposed to other therapies for glycaemic control [56-58]. Exogenous insulin has been considered to have a synergistic impact with the VEGF expressed by ischemic retina and leading vascular proliferation and the worsening of diabetes retinopathy. Included studies showed a high degree of heterogeneity in terms of population 


\section{Incidence (\%)}

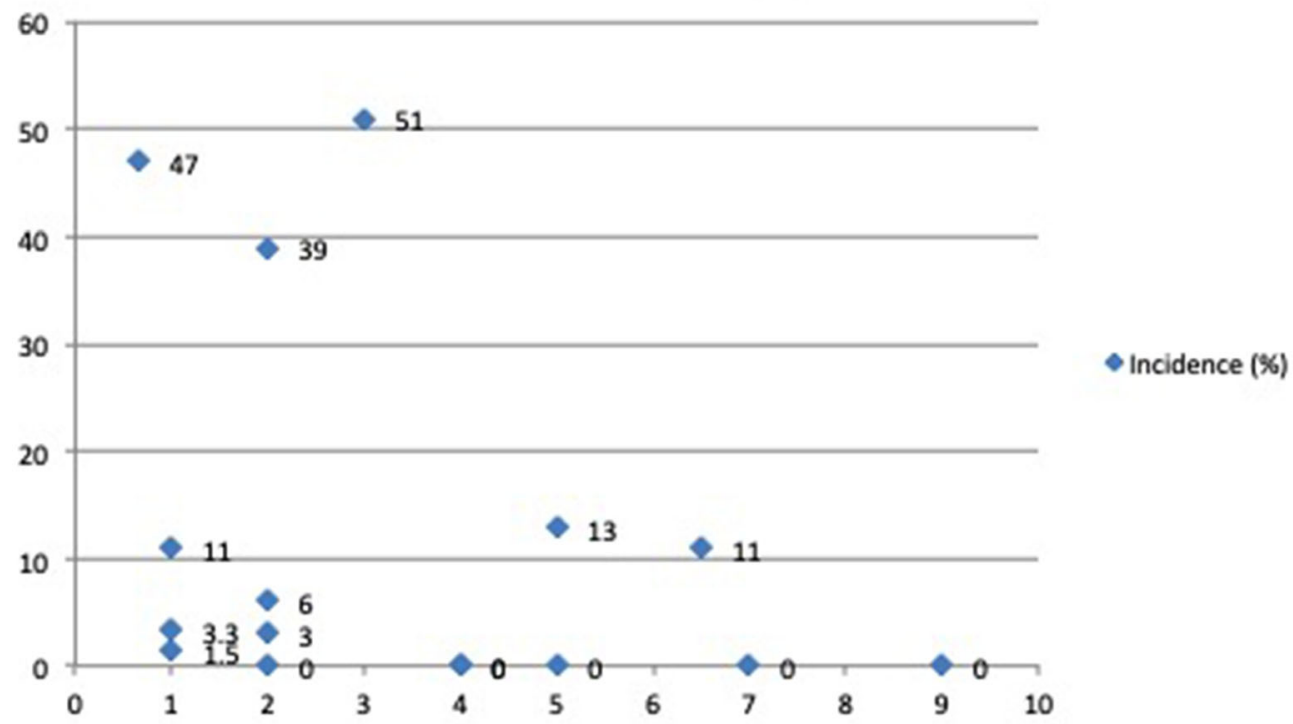

Fig. 2 Incidence rate of early worsening of diabetic retinopathy reported in the reviewed articles

characteristics, treatment regimes and timing and method of retinopathy assessment. Definition of EWDR varied across trials which may relate to changes in retinopathy grading, specific morphological changes or clinically relevant patient outcomes.

The landmark DCCT [59] trial in type 1 diabetes reported EWDR had a greater occurrence in IT compared to CT $(P<0.001)$. At 18 months, $51 \%$ of participants receiving IT had improvement in DR (DR regression). Baseline HbA1c levels were higher and larger reductions were experienced in the first 6 months in those who had the EWDR phenomenon. However, overall DR outcomes were better in the IT group. Beneficial effects of intensive treatment were observed after 10 years of follow-up with lower DR progression in the treatment group.

There are limited data for the association between the rapid/tight control of plasma glucose levels and EWDR in participants with type 2 diabetes because currently available randomized clinical trials data only present final DR classification at the end of the trial in IT or CT groups [20, 27, 42]. Unfortunately the studies included in this review did not give information about the subtype of type 2 diabetes which would provide more clinical translatability.

Other systematic reviews and meta-analyses in type 1 and 2 diabetes have shown overall benefit of IT. A recent Cochrane review included 12 clinical trials involving a total of 2230 participants with type 1 diabetes and showed that IT when compared to CT was highly effective in reducing the risk of developing microvascular diabetes complications including DR [60]. A meta-analysis of 24 studies involving 9302 participants with type 1 diabetes reported that IT reduced DR progression by nearly 33\% [61]. A meta-analysis of studies in type 2 diabetes including the ACCORD, UKPDS, AdRem and VADT studies suggested that IT was associated with a $13 \%$ of risk reduction of eye events. This review reported a composite outcome of requirement for pan-retinal photocoagulation therapy, pars plana vitrectomy development of proliferative retinopathy or progression of DR after 5 years of follow-up (HR 0.87, 95\% CI $0.76-1.00 ; P=0.04)$. Interestingly, a lower, nonsignificant rate of eye events was observed during the first year of follow-up in the IT group. The pooled hazard ratio (HR) for the primary eye outcome was 0.83 (95\% CI $0.57-1.20$; $P=0.323)$, and the annual rate of ocular events 
was $0.38 \%$ vs $0.53 \%$ in the IT group and CT groups, respectively [62].

\section{Does Baseline DR Status Predict EWDR?}

The DCCT [38] and Oslo study [29] primary prevention cohort study participants did not have any DR at the beginning of the study. Arun et al. [49] reported that after initiation of insulin treatment in type 2 diabetes, clinically significant worsening of retinopathy over a 3-year period was uncommon in those with no retinopathy $(2.6 \%)$ but occurred in $31.8 \%$ of patients with any retinopathy at baseline. A feature common to studies demonstrating progression of retinopathy is that patients having worse initial DR grade are at highest risk after intensification of glycemic control. The risk of serious worsening of retinopathy after intensive insulin therapy in patients with type 2 diabetes may have been previously overestimated. Patients with previous DR have a greater risk of EWDR and irreversible lesions. In addition, the exclusion of patients with higher grades of retinopathy from studies may lead to underestimations of the true incidence of EWDR.

\section{EWDR: Long-Term Complication or Transient Phenomena}

Our systematic review has identified evidence that EWDR is a transient phenomenon. In the Oslo study, retinal structural abnormalities including cotton-wool spots regressed in all participants who experienced a large drop of HbA1c except four patients at 1 year [29]. In a number of studies, EWDR was reported within 3-6 months of an intensive treatment which led to early eye evaluation $[29,33,38]$.

In the DCCT, EWDR occurred primarily in the secondary-intervention cohort $(n=715)$ (type 1 diabetes for $1-15$ years with mild nonproliferative DR (NPDR) with at least one microaneurysm in either eye, but no more than moderate non-proliferative DR and urinary albumin excretion of less than $200 \mathrm{mg} / 24 \mathrm{~h}$ at baseline) within 12 months of randomization [38]. EWDR was experienced by $22 \%$ in the IT group versus $13 \%$ in the CT group [38].
However, in most cases these fundus abnormalities disappeared by 18 months, and no case of early worsening resulted in serious visual loss [38]. Studies which did not detect EWDR (UKPDS, ADREM, ACCORD, VADT studies $[20,27,42,44])$ may have missed the phenomenon because their protocols lacked retinal assessment in the early stages. It is difficult to draw definite conclusions because of major differences in study designs regarding timing of retinal assessment.

\section{Lack of Imaging Consensus}

There is no widely recognized consensus for retinopathy assessment in the context of studies investigating the effect of intensification of glycaemic control. Imaging modalities, techniques and grading systems varied across the included studies. This considerable heterogeneity in assessment of DR made the comparison between studies (and meta-analysis) difficult. Dual grading with arbitration of retinal photographs by an accredited reading centre is seen as the reference standard [63]. Variation in the method of retinopathy assessment and lack of external validation are likely to have contributed to the variation in data reported.

\section{Putative Pathogenetic Mechanisms in EWDR}

A number of mechanisms are postulated for the development of EWDR.

The effect of the growth hormone and IGF-1 axis and its relevance in the pathophysiology of EWDR [18] has been studied. Chantelau et al. reported case studies and hypothesized that increasing serum insulin as well as IGF-1 may trigger VEGF-induced macular oedema with reduction of visual acuity $[58,64]$. Salgado et al. [65] studied people with type 1 diabetes reporting increased growth hormone secretion in subjects with poor glycaemic control. After improvement in glycaemic control [65], levels of IGF-binding protein 1 (IGFBP-1) were reduced and IGF-1 levels were significantly higher. Even in adolescents with newly diagnosed type 1 diabetes [66], IGF-1 levels are low 
and increase rapidly with insulin treatment. IGF-1 has a promoting effect on retinal vessel formation through an increased expression of VEGF in retinal microvascular endothelial cells $[67,68]$. Reactive oxygen species (ROS) increase the production of VEGF which leads to proliferative retinopathy by new vessel formation and blood vessel leakage [69]. It is postulated that improved glycaemic control in the presence of retinal hypoxia may lead to VEGF upregulation [70]. Indeed, Thangarajah et al. have shown that there is a blunted VEGF expression and VEGF continues to increase even after plasma glucose reduction under ischaemic conditions [71]. The hypoxia has also been shown to regulate the production of a number of angiogenic factors including platelet-derived growth factor, erythropoietin and fibroblast growth factors [72]. These specific mechanisms need to be studied in well-designed prospective cohort studies and clinical trials.

\section{LIMITATIONS AND CONCLUSIONS}

This systematic review was limited to published articles in English. There is considerable heterogeneity in the literature reporting retinopathy in patients receiving intensive glycaemic control and thus a meta-analysis was not possible.

There have been many theories proposed to explain EWDR, but unfortunately all are found to be inconclusive. There are knowledge gaps due to the lack of adequate baseline and followup retinal imaging data in several large-scale studies. Non-clinical studies might help address the gaps and lead to stronger theories, but suitable animal models might be limited. Not only the magnitude of HbA1c decrease but also the rapidness of this change is an important issue which is worth evaluating further.

Interventional studies which include intensive glycaemic control should report retinopathy and visual outcomes using standardized protocols. If possible, assessment should include $\log$ MAR visual acuity, digital retinal photographs graded in an accredited reading centre and optical coherence tomography (OCT) of the macula. Assessment should occur at baseline and at least quarterly if identification of EWDR is an aim of the study.

EWDR has implications in clinical practice. Guidelines from the American Diabetes Association suggest at least annual eye examinations for patients with DR, while guidelines from the Royal College of Ophthalmologists recommend annual eye examinations for mild-to-moderate DR and examinations every 4-6 months for moderately severe-to-very severe DR [73, 74]. Guideline revisions may be required for patients with DR and poor glycaemic control prior to initiation of intensive glycaemic control. Until more evidence becomes available, the general goal of target $\mathrm{HbA} 1 \mathrm{c}<59 \mathrm{mmol} / \mathrm{mol} \quad(7 \%)$ should be considered, however.

This review has identified a range of estimates for incidence of EWDR and risk factors for the condition. Intensification of glycaemic control does lead to EWDR in a proportion of people; however, the precise incidence remains unclear because of methodological differences in the reported studies. Interventional studies should report retinopathy and visual outcomes using standardized protocols. Whether EWDR leads to long-term adverse visual outcomes remains unclear and is an important priority for future research.

\section{ACKNOWLEDGEMENTS}

Funding. No funding or sponsorship was received for this study or publication of this article.

Authorship. All named authors meet the International Committee of Medical Journal Editors (ICMJE) criteria for authorship for this article, take responsibility for the integrity of the work as a whole, and have given their approval for this version to be published.

Author Contributions. All authors contributed to the study conception and design. Uazman Alam, Phillip Burgess and Simon Harding had the idea for the article. Handan Akil and Jamie Burgess performed the literature search and data analysis. The first draft of the 
manuscript was written by Handan Akil and all authors commented on previous versions of the manuscript. All authors read and approved the final manuscript.

Disclosures. Handan Akil, Jamie Burgess, Sarah Nevitt, Simon P Harding, Uazman Alam, Philip Burgess have nothing to disclose.

Compliance with Ethics Guidelines. This article is based on previously conducted studies and does not contain any new studies with human participants or animals performed by any of the authors.

Data Availability. Data sharing is not applicable to this article as no datasets were generated or analyzed.

Open Access. This article is licensed under a Creative Commons Attribution-NonCommercial 4.0 International License, which permits any non-commercial use, sharing, adaptation, distribution and reproduction in any medium or format, as long as you give appropriate credit to the original author(s) and the source, provide a link to the Creative Commons licence, and indicate if changes were made. The images or other third party material in this article are included in the article's Creative Commons licence, unless indicated otherwise in a credit line to the material. If material is not included in the article's Creative Commons licence and your intended use is not permitted by statutory regulation or exceeds the permitted use, you will need to obtain permission directly from the copyright holder. To view a copy of this licence, visit http://creativecommons.org/licenses/by$\mathrm{nc} / 4.0 /$.

\section{REFERENCES}

1. Lee R, Wong TY, Sabanayagam C. Epidemiology of diabetic retinopathy, diabetic macular edema and related vision loss. Eye Vis. 2015. https://doi.org/10. 1186/s40662-015-0026-2.

2. Wong TY, Cheung CMG, Larsen M, Sharma S, Simó R. Diabetic retinopathy. Nat Rev Dis Prim. 2016. https://doi.org/10.1038/nrdp.2016.12.
3. International Diabetes Federation. IDF Diabetes Atlas, 9th edn. Brussels: International Diabetes Federation; 2019. http://www.diabetesatlas.org/.

4. Simó R, Stitt AW, Gardner TW. Neurodegeneration in diabetic retinopathy: does it really matter? Diabetologia. 2018. https://doi.org/10.1007/s00125018-4692-1.

5. Yau JWY, Rogers SL, Kawasaki R, et al. Global prevalence and major risk factors of diabetic retinopathy. Diabetes Care. 2012;35(3):556-64. https://doi.org/10.2337/dc11-1909.

6. Cho NH, Shaw JE, Karuranga S, et al. IDF Diabetes Atlas: Global estimates of diabetes prevalence for 2017 and projections for 2045. Diabetes Res Clin Pract. 2018;138:271-81.

7. Wang W, Lo ACY. Diabetic retinopathy: pathophysiology and treatments. Int J Mol Sci. 2018. https://doi.org/10.3390/ijms19061816.

8. Dhatariya KK, Wha-Pun Sin ELP, Cheng JOS, et al. The impact of glycaemic variability on wound healing in the diabetic foot-a retrospective study of new ulcers presenting to a specialist multidisciplinary foot clinic. Diabetes Res Clin Pract. 2018. https://doi.org/10.1016/j.diabres.2017.10.022.

9. Risso A, Mercuri F, Quagliaro L, Damante G, Ceriello A. Intermittent high glucose enhances apoptosis in human umbilical vein endothelial cells in culture. Am J Physiol. 2001. https://doi.org/10. 1152/ajpendo.2001.281.5.e924.

10. Hietala K, Waden J, Forsblom C, et al. HbA1c variability is associated with an increased risk of retinopathy requiring laser treatment in type 1 diabetes. Diabetologia. 2013. https://doi.org/10. 1007/s00125-012-2816-6.

11. Miller KM, Foster NC, Beck RW, et al. Current state of type 1 diabetes treatment in the U.S.: updated data from the $1 \mathrm{~d}$ exchange clinic registry. Diabetes Care. 2015. https://doi.org/10.2337/dc15-0078.

12. National Institute for Health and Care Excellence (NICE). Type 2 diabetes in adults: management (NICE guideline 28). 2015. https://www.nice.org. uk/guidance/ng28/evidence.

13. Stratton IM, Kohner EM, Aldington SJ, et al. UKPDS 50: Risk factors for incidence and progression of retinopathy in type II diabetes over 6 years from diagnosis. Diabetologia. 2001. https://doi.org/10. 1007/s001250051594.

14. Aiello LP. Diabetic retinopathy and other ocular findings in the diabetes control and complications trial/epidemiology of diabetes interventions and 
complications study. Diabetes Care. 2014. https:// doi.org/10.2337/dc13-2251.

15. National Institute for Health and Care Excellence (NICE). Type 1 diabetes in adults: diagnosis and management (NICE guideline 17). 2015. https:// www.nice.org.uk/guidance/ng17.

16. Hooymans JMM, Ballegooie EV, Schweitzer NMJ, Doorenbos H, Reitsma WD, Sluiter WJ. Worsening of diabetic retinopathy with strict control of blood sugar. Lancet. 1982. https://doi.org/10.1016/S01406736(82)90464-0.

17. Marso SP, Bain SC, Consoli A, et al. Semaglutide and cardiovascular outcomes in patients with type 2 diabetes. N Engl J Med. 2016. https://doi.org/10. 1056/NEJMoa1607141.

18. Kondo T, Vicent D, Suzuma K, et al. Knockout of insulin and IGF-1 receptors on vascular endothelial cells protects against retinal neovascularization. J Clin Invest. 2003. https://doi.org/10.1172/ JCI200317455.

19. Moher D, Shamseer L, Clarke M, et al. Preferred reporting items for systematic review and metaanalysis protocols (PRISMA-P) 2015 statement. Syst Rev. 2016. https://doi.org/10.1186/2046-4053-4-1.

20. Beulens JWJ, Patel A, Vingerling JR, et al. Effects of blood pressure lowering and intensive glucose control on the incidence and progression of retinopathy in patients with type 2 diabetes mellitus: a randomised controlled trial. Diabetologia. 2009. https://doi.org/10.1007/s00125-009-1457-x.

21. Varadhan L, Humphreys T, Hariman C, Walker AB, Varughese GI. GLP-1 agonist treatment: implications for diabetic retinopathy screening. Diabetes Res Clin Pract. 2011. https://doi.org/10.1016/j. diabres.2011.08.017.

22. Hoy D, Brooks P, Woolf A, et al. Assessing risk of bias in prevalence studies: modification of an existing tool and evidence of interrater agreement. J Clin Epidemiol. 2012. https://doi.org/10.1016/j. jclinepi.2011.11.014.

23. Alberti KG, Definition Zimmer PZ. diagnosis and classification of diabetes mellitus and its complications. Part 1: diagnosis and classification of diabetes mellitus provisional report of a World Health Organisation consultation. Diabet Med. 1998;15(7): 539-53. https://doi.org/10.1002/(SICI)10969136(199807)15:7\%3c539::AID-DIA668\%3e3.0. CO;2-S.

24. World Health Organization \& International Diabetes Federation. (2006). Definition and diagnosis of diabetes mellitus and intermediate hyperglycaemia : report of a WHO/IDF consultation. World
Health Organization. https://apps.who.int/iris/ handle/10665/43588.

25. American Diabetes Association. Standard medical care in diabetes 2018. J Clin Appl Res Educ. 2018. https://doi.org/10.2337/dc18-Sint01.

26. Lauritzen T, Larsen HW, Frost-Larsen K, Deckert T, The Steno Study Group. Effect of 1 year of nearnormal plasma glucose levels on retinopathy in insulin-dependent diabetics. Lancet. 1983. https:// doi.org/10.1016/S0140-6736(83)92585-0.

27. Turner R. Intensive blood-glucose control with sulphonylureas or insulin compared with conventional treatment and risk of complications in patients with type 2 diabetes (UKPDS 33). Lancet. 1998. 6736(98)07019-6.

28. Lauritzen T, Frost-Larsen K, Larsen HW, Deckert T. Two-year experience with continuous subcutaneous insulin infusion in relation to retinopathy and neuropathy. Diabetes. 1985. https://doi.org/10. 2337/diab.34.3.s74.

29. Dahl-Jørgensen K, Brinchmann-Hansen O, Hanssen KF, Sandvik L, Aagenæs O. Rapid tightening of plasma glucose control leads to transient deterioration of retinopathy in insulin dependent diabetes mellitus: the Oslo study. Br Med J (Clin Res Ed). 1985. https://doi.org/10.1136/bmj.290.6471.811.

30. Brinchmann-Hansen O, Dahl-Jorgensen K, Sandvik L, Hanssen KF. Plasma glucose concentrations and progression of diabetic retinopathy: the seven year results of the Oslo study. Br Med J. 1992;. https:// doi.org/10.1136/bmj.304.6818.19.

31. The Kroc Collaborative Study Group. Plasma glucose control and the evolution of diabetic retinopathy and albuminuria: a preliminary multicenter trial. N Engl J Med. 1984;311:365-72. https://doi.org/10.1056/NEJM198408093110604.

32. The Kroc Collaborative Study Group. Diabetic retinopathy after two years of intensified insulin treatment: follow-up of the Kroc collaborative study. JAMA. 1988;260(1):37-41. https://doi.org/ 10.1001/jama.1988.03410010045032.

33. The Diabetes Control and Complications Trial Research Group. Early worsening of diabetic retinopathy in the diabetes control and complications trial. Arch Ophthalmol. 1998;116(7):874-86. https://doi.org/10.1001/archopht.116.7.874.

34. Klefter ON, Hommel E, Munch IC, Nørgaard K, Madsbad S, Larsen M. Retinal characteristics during 1 year of insulin pump therapy in type 1 diabetes: a prospective, controlled, observational study. Acta 
Ophthalmol. 2016;. https://doi.org/10.1111/aos. 13066.

35. Nathan DM, Genuth S, Lachin J, et al. The effect of intensive treatment of diabetes on the development and progression of long-term complications in insulin-dependent diabetes-mellitus. N Engl J Med. 1993;329(14):977-86.

36. Dahl-Jørgensen K, Brinchmann-Hansen O, Hanssen KF, Sandvik L, Aagenaes O. Rapid tightening of plasma glucose control leads to transient deterioration of retinopathy in insulin dependent diabetes mellitus: the Oslo study. Br Med J (Clin Res Ed). $1985 ; 290(6471): 811-5$.

37. Reichard P, Pihl M, Rosenqvist U, Sule J. Complications in IDDM are caused by elevated plasma glucose level: the Stockholm diabetes intervention study (SDIS) at 10-year follow up. Diabetologia. 1996. https://doi.org/10.1007/s001250050602.

38. The Diabetes Control and Complications Trial Research Group. The effect of intensive treatment of diabetes on the development and progression of long-term complications in insulin-dependent diabetes mellitus. N Engl J Med. 1993;329:977-86. https://doi.org/10.1056/NEJM199309303291401.

39. Early Treatment Diabetic Retinopathy Study Research Group. Photocoagulation for diabetic macular edema: early treatment diabetic retinopathy study report number 1. Arch Ophthalmol. 1985;103(12):1796-806. https://doi.org/10.1001/ archopht.1985.01050120030015.

40. Aiello LP. Diabetic retinopathy and other ocular findings in the diabetes control and complications trial/epidemiology of diabetes interventions and complications study. Diabetes Care. 2014;37(1): 17-23. https://doi.org/10.2337/dc13-2251.

41. Lachin JM, White NH, Hainsworth DP, Sun W, Cleary PA, Nathan DM. Effect of intensive diabetes therapy on the progression of diabetic retinopathy in patients with type 1 diabetes: 18 years of followup in the DCCT/EDIC. Diabetes. 2015. https://doi. org/10.2337/db14-0930.

42. Chew EY, Ambrosius WT, David MD, et al. Effects of medical therapies on retinopathy progression in type 2 diabetes. N Engl J Med. 2010. https://doi.org/ 10.1056/NEJMoa1001288.

43. Chew EY, Davis MD, Danis PD, et al. The effects of medical management on the progression of diabetic retinopathy in persons with type 2 diabetes: the action to control cardiovascular risk in diabetes (ACCORD) eye study. Ophthalmology. 2014. https://doi.org/10.1016/j.ophtha.2014.07.019.
44. Azad N, Bahn GD, Emanuele NV, et al. Association of plasma glucose control and lipids with diabetic retinopathy in the Veterans Affairs Diabetes Trial (VADT). Diabetes Care. 2016. https://doi.org/10. 2337/dc15-1897.

45. Vilsbøll T, Bain SC, Leiter LA, et al. Semaglutide, reduction in glycated haemoglobin and the risk of diabetic retinopathy. Diabetes Obes Metab. 2018. https://doi.org/10.1111/dom.13172.

46. Henricsson M, Nilsson A, Janzon L, Groop L. The effect of glycaemic control and the introduction of insulin therapy on retinopathy in non-insulin-dependent diabetes mellitus. Diabet Med. 1997. https://doi.org/10.1002/(SICI)1096-

9136(199702)14:2\%3c123::AID-DIA306\%3e3.0. CO;2-U.

47. Henricsson M, Berntorp K, Berntorp E, Fernlund P, Sundkvist G. Progression of retinopathy after improved metabolic control in type 2 diabetic patients: relation to IGF-1 and hemostatic variables. Diabetes Care. 1999. https://doi.org/10.2337/ diacare.22.12.1944.

48. Shurter A, Genter P, Ouyang D, Ipp E. Euglycemic progression: worsening of diabetic retinopathy in poorly controlled type 2 diabetes in minorities. Diabetes Res Clin Pract. 2013. https://doi.org/10. 1016/j.diabres.2013.03.018.

49. Arun CS, Pandit R, Taylor R. Long-term progression of retinopathy after initiation of insulin therapy in type 2 diabetes: an observational study. Diabetologia. 2004. https://doi.org/10.1007/s00125-0041473-9.

50. Egan A, Byrne M. Effects of medical therapies on retinopathy progression in type 2 diabetes. Ir Med J. 2011. https://doi.org/10.1016/j.yoph.2010.12.007.

51. Azad N, Agrawal L, Emanuele NV, Klein R, Bahn GD, Reaven P. Association of plasma glucose control and pancreatic reserve with diabetic retinopathy in the Veterans Affairs Diabetes Trial (VADT). Diabetologia. 2014. https://doi.org/10.1007/ s00125-014-3199-7.

52. Kohner EM, Stratton IM, Aldington SJ, Holman RR, Matthews DR. Relationship between the severity of retinopathy and progression to photocoagulation in patients with type 2 diabetes mellitus in the UKPDS (UKPDS 52). Diabet Med. 2001. https://doi. org/10.1046/j.1464-5491.2001.00458.x.

53. Marso SP, Daniels GH, Brown- Frandsen K, et al. Liraglutide and cardiovascular outcomes in type 2 diabetes. N Engl J Med. 2016. https://doi.org/10. 1056/NEJMoa1603827. 
54. Bain SC, Klufas MA, Ho A, Matthews DR. Worsening of diabetic retinopathy with rapid improvement in systemic glucose control: a review. Diabetes Obes Metab. 2019. https://doi.org/10.1111/dom.13538.

55. Henricsson M, Berntorp K, Fernlund P, Sundkvist G. Progression of retinopathy in insulin-treated type 2 diabetic patients. Diabetes Care. 2002. https://doi. org/10.2337/diacare.25.2.381.

56. Rosenstock J, Schwartz SL, Clark CM, Park GD, Donley DW, Edwards MB. Basal insulin therapy in type 2 diabetes: 28-week comparison of insulin glargine (HOE 901) and NPH insulin. Diabetes Care. 2001. https://doi.org/10.2337/diacare.24.4.631.

57. Mayer D, Shukla A, Enzmann H. Proliferative effects of insulin analogues on mammary epithelial cells. Arch Physiol Biochem. 2008. https://doi.org/10. 1080/13813450801900645.

58. Chantelau E. Evidence that upregulation of serum IGF-1 concentration can trigger acceleration of diabetic retinopathy. Br J Ophthalmol. 1998. https://doi.org/10.1136/bjo.82.7.725.

59. The Diabetes Control and Complications Trial Research Group. Early worsening of diabetic retinopathy in the Diabetes Control and Complications Trial. [Erratum appears in Arch Ophthalmol 1998 Nov;116(11):1469]. Arch Ophthalmol. 1998;116(7):874-86.

60. Fullerton B, Jeitler K, Seitz M, Horvath K, Berghold A, Siebenhofer A. Intensive glucose control versus conventional glucose control for type 1 diabetes mellitus. Cochrane Database Syst Rev. 2014. https://doi.org/10.1002/14651858.CD009122. pub2.

61. Virk SA, Donaghue KC, Wong TY, Craig ME. Interventions for diabetic retinopathy in type 1 diabetes: systematic review and meta-analysis. Am J Ophthalmol. 2015. https://doi.org/10.1016/j.ajo.2015. 07.024 .

62. Zoungas S, Arima H, Gerstein HC, et al. Effects of intensive glucose control on microvascular outcomes in patients with type 2 diabetes: a metaanalysis of individual participant data from randomised controlled trials. Lancet Diabetes Endocrinol. 2017;5(6):431-7. https://doi.org/10.1016/ S2213-8587(17)30104-3.

63. Tufail A, Rudisill C, Egan C, et al. Automated diabetic retinopathy image assessment software: diagnostic accuracy and cost-effectiveness compared with human graders. Ophthalmology. 2017. https://doi.org/10.1016/j.ophtha.2016.11.014.
64. Chantelau E, Meyer-Schwickerath R, Klabe K. Downregulation of serum IGF-1 for treatment of early worsening of diabetic retinopathy: a longterm follow-up of two cases. Ophthalmologica. 2010. https://doi.org/10.1159/000260231.

65. Salgado LR, Semer M, Nery M, et al. Effect of glycemic control on growth hormone and IGFBP-1 secretion in patients with type I diabetes mellitus. J Endocrinol Invest. 1996. https://doi.org/10.1007/ BF03349888.

66. Chisalita SI, Ludvigsson J. Insulin-like growth factor-1 at diagnosis and during subsequent years in adolescents with type 1 diabetes. J Diabetes Res. 2018. https://doi.org/10.1155/2018/8623560.

67. Fukuda R, Hirota K, Fan F, Do Jung Y, Ellis LM, Semenza GL. Insulin-like growth factor 1 induces hypoxia-inducible factor 1-mediated vascular endothelial growth factor expression, which is dependent on MAP kinase and phosphatidylinositol 3-kinase signaling in colon cancer cells. J Biol Chem. 2002. https://doi.org/10.1074/jbc. M203781200.

68. Hellström A, Engstörm E, Hard A, et al. Postnatal serum insulin-like growth factor I deficiency is associated with retinopathy of prematurity and other complications of premature birth. Pediatrics. 2003. https://doi.org/10.1542/peds.112.5.1016.

69. Hanaire-Broutin H, Sallerin-Caute B, Poncet MF, et al. Effect of intraperitoneal insulin delivery on growth hormone binding protein, insulin-like growth factor (IGF)-I, and IGF-binding protein-3 in IDDM. Diabetologia. 1996. https://doi.org/10.1007/ s001250050604.

70. Kennedy A, Frank RN. The influence of glucose concentration and hypoxia on VEGF secretion by cultured retinal cells. Curr Eye Res. 2011. https:// doi.org/10.3109/02713683.2010.521968.

71. Thangarajah H, Yao D, Chang EI, et al. The molecular basis for impaired hypoxia-induced VEGF expression in diabetic tissues. Proc Natl Acad Sci USA. 2009. https://doi.org/10.1073/pnas. 0906670106.

72. Duh EJ, Sun JK, Stitt AW. Diabetic retinopathy: current understanding, mechanisms, and treatment strategies. JCI insight. 2017. https://doi.org/10. 1172/jci.insight.93751.

73. Solomon SD, Chew E, Duh EJ, et al. Diabetic retinopathy: a position statement by the American Diabetes Association. Diabetes Care. 2017. https:// doi.org/10.2337/dc16-2641. 
74. Ghanchi F, Bailey C, Chakravarthy U, et al. The Royal College of Ophthalmologists diabetic retinopathy guidelines. London: The Royal College of Ophthalmologists; 2012. https://www.rcophth.
ac.uk/wp-content/uploads/2021/08/2012-SCI-267Diabetic-Retinopathy-Guidelines-December-2012. pdf. 